\title{
Grupo maturidade ativa e o seu significado para as alunas do grupo do Sesc de Santo Ângelo - RS
}

\author{
Active maturity group and its meaning for the students of the \\ Sesc group of Santo Ângelo - RS
}

'Leticia Cristiane Patan Ferraz, ${ }^{2}$ Chilon Rodrigues, ${ }^{3}$ Eliana
Zellmer Poerschke Farencena, ${ }^{4}$ Viviana da Rosa Deon.

\section{RESUMO}

Introdução: O aumento da expectativa de vida da população e a preocupação com o envelhecimento têm proporcionado novas investigações científicas a esse respeito em todos os segmentos profissionais da sociedade. Objetivo: analisar o significado do grupo Maturidade Ativa do Serviço Social do Comércio (SESC), em Santo Ângelo, para as mulheres entre 50 e 65 anos de idade que frequentam este grupo. Materiais e métodos: Este estudo caracteriza-se como uma pesquisa descritiva exploratória com abordagem qualitativa, sendo a coleta de dados feita através da aplicação de questionário estruturado contendo perguntas abertas, cujas respostas obtidas foram analisadas através do método de categorização a partir da análise de frequência e posterior classificação em 4 (quatro) categorias. Resultados: constatou-se que, para as mulheres que frequentam o grupo, este possui uma contribuição significativa no equilíbrio emocional, autoestima, integração social, ocupação, prática de atividade física, promoção e prevenção da saúde e em um estilo de vida ativo. Conclusão: as atividades realizadas conseguiram superar os objetivos do projeto Maturidade Ativa do SESC, em Santo Ângelo em todos os aspectos. Adicionalmente, houve aumento significativo na expectativa de vida das participantes, atrelada a uma vida mais saudável, com maior disposição física e mental e, consequente, melhor qualidade de vida.

Palavras-chave: Envelhecimento saudável. Estilo de vida ativo. Expectativa de vida.
'Professora de Educação Física. Pós-graduada Lato Sensu em Fisiologia do Exercício pela AVM Faculdade Integrada, Rio de Janeiro/RJ. Universidade de Gurupi/TO, Brasil.

Email: letipatan@gmail.com

2 Professor de Educação Física. Universidade de Gurupi/TO, Brasil.

Email:

chillon.rodrigues@hotmail.com

3Professora Adjunta III do departamento de Educação Física da Universidade de Gurupi (TO), Brasil. Mestre em Ciência da Motricidade Humana/Universidade Castelo Branco-RJ. $\quad$ E-mail: elianafarencena@yahoo.com.br

${ }^{4}$ Professora tempo integral da Universidade Regional Integrada do Alto Uruguai e das Missões - URI - CAMPUS SANTO ÂNGELO. Mestre em Educação nas Ciências pela Unijui - Ijuí. E-mail: vivianadeon@san.uri.br

\section{ABSTRACT}

Introduction: The increase in the life expectancy of the population and the concern with aging have provided new scientific investigations in this respect in all professional segments of society. Objective: to analyze the meaning of the Grupo Maturidade Ativa of the Serviço Social do Comércio (SESC), in Santo Ângelo to women between 50 and 65 years old who attend this group. Materials and methods: This study is characterized as an exploratory descriptive research with a qualitative approach, data collection was done through the application of a semi-structured questionnaire with open questions, whose answers were analyzed through the categorization method from a frequency analysis and classified in 4 (four) categories. Results: it was found that, for women attending the Active Maturity Group, has a significant contribution to emotional balance, self-esteem, social integration, occupation, physical activity practice, promotion and prevention of health and an active lifestyle. Conclusion: concludes that the Group's activities meet its expectations. Additionally, there was a significant increase in the participants' life expectancy, linked to a healthier life, with greater physical and mental disposition and, consequently, a better quality of life.

Keywords: Healthy aging. Active lifestyle. Life expectancy. 


\section{INTRODUÇAO}

A vida é um ciclo de nascer, crescer, amadurecer, envelhecer e morrer, no entanto, não significa que a velhice deva estar diretamente associada à doença e à morte. Muito das representações sociais que se tem da terceira idade apontam para esses dois tópicos como centrais. No entanto, esses podem ocorrer em qualquer um dos ciclos de vida. Repensar a terceira idade é um ponto crucial na maturidade. Esse é um momento de vida no qual há a necessidade de reconstruir dignidade, direitos, implementando a cidadania e não um momento de encerramento, mas de reativação de novos sentidos ${ }^{1}$.

Segundo a $\mathrm{OMS}^{2}$ o envelhecimento pode ser conceituado como a soma de todas as alterações nos aspectos biológicos, psicológicos e sociais, que depois de alcançar a idade adulta e ultrapassar a idade de desempenho máximo, levam a uma redução gradual das capacidades de desempenho e exigem novas adaptações psicofisiológicas do indivíduo.

O enfoque atual no estudo do envelhecimento humano demonstra também que é importante perceber a velhice como uma experiência heterogênea. Ser velho envolve uma complexidade de fatores de ordem biológica, psicológica e social. Na sociedade atual, a identidade dos idosos se constrói apenas pela contraposição à identidade de jovem, refutando as qualidades: atividade, força, memória, beleza, potência e produtividade ${ }^{3}$.

Segundo Nahas ${ }^{4}$ a qualidade de vida difere de pessoa para pessoa, mas o seu conceito geral envolve: estado de saúde, longevidade, satisfação no trabalho, salário, lazer, relações familiares, disposição, prazer, espiritualidade e um programa de atividades físicas direcionado às pessoas idosas pode contemplar vários desses fatores, principalmente por fazerem parte de um grupo. Porém, ressaltasse que é importante que a pessoa envelheça com qualidade de vida e saúde para que possa viver de forma tranquila e feliz ${ }^{5}$. A definição de atividade física caracteriza-se como sendo todo e qualquer movimento corporal produzido pela musculatura esquelética (voluntária) que resulta em gasto energético acima dos níveis de repouso ${ }^{6}$.

A atividade física surge, deste modo, como um elemento importante para o desenvolvimento da autovalorização. Neste sentido, o SESC, que foi a primeira instituição a realizar trabalho com idosos no Brasil e, por ser uma instituição social, tem grande interesse na melhoria de seus serviços prestados a sociedade, buscando através de projetos tais como o "Maturidade Ativa" atender um público específico de pessoas idosas da comunidade proporcionando integração, bem estar físico e mental, através de um lugar 
dedicado à realização das atividades físicas e recreativas não somente para fins de exercitar-se, mas também como um espaço dedicado à convivência, comunicação, no qual os idosos possam compartilhar e conversar.

A origem dessa preocupação dá-se pelo fato de se observar, a busca pela possibilidade de se ter uma vida fisicamente ativa, sendo capaz de realizar atividades da vida diária e exercitar-se de maneira satisfatória, encontrando uma melhor qualidade de vida.

A participação de idosos em atividades em grupo representa um aspecto diferencial, no rumo de suas histórias de vida, pois beneficia a experiência de um estado de plenitude e bem-estar, proporcionando um reforço no sentido existencial, auxiliando a entender o futuro como uma história em construção conforme Victor et al, comenta.

A presente pesquisa teve como objetivo analisar o significado do grupo Maturidade Ativa do SESC Santo Ângelo para as mulheres entre 50 e 65 anos de idade que frequentavam este grupo. Partindo do objetivo geral, o estudo teve como objetivos específicos investigar o que significava "envelhecer" para as mulheres do grupo; investigar o que a participação no grupo significava para essas mulheres no processo de envelhecimento; verificar se as atividades físicas realizadas estavam satisfazendo as expectativas e verificar se os objetivos do Projeto estavam sendo atingidos.

\section{MATERIAIS E METODOS}

Este estudo caracterizou-se como um estudo descritivo exploratório, com uma abordagem qualitativa ${ }^{7}$. A pesquisa qualitativa busca compreender o significado para os participantes de uma experiência em um ambiente específico e a forma com a qual os componentes combinam-se para formar um todo ${ }^{7}$. A pesquisa descritiva é um estudo de status e é amplamente utilizada na educação e nas ciências comportamentais ${ }^{7}$. O seu valor está baseado na premissa de que os problemas podem ser resolvidos e as práticas melhoradas por meio da observação, análise e descrição objetivas e completas. O método mais comum da pesquisa descritiva é o estudo exploratório (survey), o qual inclui questionários, entrevistas pessoais, surveys pelo telefone e surveys normativos.

O presente estudo foi feito com alunas que frequentavam o grupo Maturidade Ativa do SESC de Santo Ângelo, totalizando 50 alunas na faixa etária de 50 a 65 anos de idade. 
Na coleta de dados foi utilizado um questionário estruturado com questões abertas, sendo o mesmo validado através de um estudo piloto para verificar se as questões estavam de acordo com a problematização do presente estudo. Selecionou-se aleatoriamente, por sorteio, 10 mulheres que faziam parte do grupo para que respondessem o questionário a fim de verificar se o entendimento das questões, e, se as respostas atendiam as necessidades do estudo.

O questionário foi aplicado nas 50 mulheres que frequentavam o grupo. Foi solicitado as participantes que respondessem por escrito o questionário, sendo aplicado em uma sala reservada, nas dependências do SESC de Santo Ângelo, em uma terça-feira no turno da manhã. Antes do início da aplicação foi realizada a explicação da pesquisa e entregue o Termo de consentimento livre e esclarecido para ser assinado, o qual uma via ficou com a pesquisadora e a outra via com as pesquisadas. A pesquisadora manteve-se presente durante a aplicação do questionário para esclarecimento de dúvidas. Cada participante respondia individualmente, sem poder se manifestar em voz alta ou conversar com as demais colegas.

Esta pesquisa foi submetida à apreciação do Comitê de Ética em Pesquisa e foi aprovada pela Universidade Regional Integrada do Alto Uruguai e das Missões - Campus de Santo Ângelo/RS. O número de aprovação é 009-04/TCH/07.

A realização deste se efetivou por meio da análise de frequência das respostas posteriormente agrupadas em categorias, e em análise estatística descritiva dos dados para melhor visualização das respostas. Sendo assim, as respostas foram divididas em quatro categorias: envelhecimento, o qual subdivide-se em: experiência de vida e consequência natural, idade cronológica, liberdade de aproveitar a vida e saúde; significado do grupo Maturidade Ativa, o qual subdivide-se em: ter um grupo, ocupação e prática de atividade física; expectativas e atividades realizadas, o qual subdivide-se em: estilo de vida ativo e promoção da saúde e a última categoria: projeto SESC.

Essas categorias foram analisadas de forma que se diferencie a contribuição individual para os objetivos da pesquisa. A análise dos resultados foi realizada através do método de categorias ${ }^{7}$, o qual consiste na análise do domínio a partir de recortes conceituais que permitem determinar a identidade dos conceitos (categorias) que fazem parte deste domínio. Os dados foram estudados e categorizados de forma a permitir a análise por meio de categorias, como parte do processo indutivo ${ }^{7}$. 


\section{RESULTADOS E DISCUSSÁO}

A partir das respostas analisadas, em cada categoria, observou-se que envelhecer significa chegar a uma determinada idade na qual a experiência de vida é o que interessa, é alcançar mais uma etapa da vida, aceitar a idade e estar de bem com a vida, ter vivido as diversas etapas da vida e sentir que se chega nessa idade com experiências, algumas limitações, mas com saúde, sendo encarado como um processo natural do ser humano.

A partir da experiência de vida, à imagem que se tem hoje da velhice é ainda muito pessimista. Associa-se sempre à pessoa que envelhece a ideia de decadência física, psíquica e social, configurando-se uma fase de perdas que se sobrepõe aos ganhos, como sabedoria, experiência e liberdade ${ }^{8}$. Levando em consideração a citação acima pode-se observar que algumas mulheres embora reconheçam que estão envelhecendo preferem à palavra experiência ao invés de idoso: "\{...\} não gosto da palavra idoso, prefiro experiente, vivido. Idoso lembra alguém que já está indo, se preparando para a partida. (Aluna A).

Promover o envelhecimento saudável é tarefa complexa a qual envolve a conquista de uma boa qualidade de vida e amplo acesso a serviços que possibilitem lidar bem com as questões do envelhecimento, com base no conhecimento hoje disponível. É vital, também, ampliar a consciência sobre a saúde e o processo de envelhecimento ao mesmo tempo fortalecendo e instrumentalizando a população em suas lutas por cidadania e justiça social ${ }^{5}$.

As pessoas podem retardar ou antecipar o envelhecimento em função das condições de vida e de trabalho nas quais elas se encontram submetidas. E é de senso comum que, na medida em que as pessoas vivem, vão adquirindo mais experiência. Assim sendo, podese correlacionar às questões relativas ao envelhecimento com as questões relativas à experiência.

A idade cronológica sempre é uma medida arbitrária e não muito exata, de modo que o uso de um número único para limiar lhe daria um status enganadoramente objetivo. Partindo dessa premissa, outra questão a considerar é o fator cronológico, de que idade elas gostariam de ter hoje ou que idade elas se consideram ter. Essas questões são tratadas de forma a considerar que o envelhecimento pode ser entendido como a consequência da passagem do tempo ou como o processo cronológico pelo qual um indivíduo se torna mais velho. 
A idade é usualmente e arbitrariamente medida em anos e, na maioria das sociedades, o aniversário de nascimento é considerado um evento importante. Pode-se considerar como algo positivo quando as próprias mulheres da pesquisa observavam que isso é apenas algo que está atrelado ao tempo pois o que importa é como elas estão vivendo: "\{...\} tenho mais ou menos a mesma idade cronológica porque amadureci bastante, mudei o meu pensar e agir para melhor e aceito a minha idade". (Aluna B). Questionando a idade cronológica das mulheres pesquisadas, foi-se indagado quantos anos elas consideravam ter e o motivo. Visto que as diferentes classificações apontam as idades/etapas em que o ser humano se encontra no processo de envelhecimento.

No entanto, qualquer que seja a idade definida dentro de contextos diferentes, é importante reconhecer que conforme a pesquisa as mulheres relataram que a idade cronológica não é um marcador preciso para as mudanças que acompanham o envelhecimento. Existem variações significativas relacionadas ao estado de saúde, participação e níveis de independência entre pessoas mais velhas que possuem a mesma idade.

A adoção de estilos de vida saudáveis e a participação ativa no cuidado da própria saúde são importantes em todos os estágios da vida. Um dos mitos do envelhecimento é de que é tarde demais para se adotar esses estilos nos últimos anos de vida. Partindo dessas considerações, tem-se a questão do que mais agrada as mulheres na idade em que se encontram hoje pois, para essas mulheres, estar nessa fase da vida, não se consideravam estar na velhice, e que os efeitos do tempo estão somente na idade cronológica, sendo que a cabeça é jovem, e assim dando-se mais importância à experiência já adquirida. Sendo assim, agora elas podem aproveitar a vida de forma diferente, com estabilidade em todos os sentidos.

O processo de envelhecimento ocorre diferentemente para as pessoas, dependendo de seu ritmo e da época de sua vida, pois, a velhice não é um período caracterizado só por perdas e limitações ${ }^{9}$. Embora aumente a probabilidade de doenças e limitações biológicas, é possível manter e aprimorar a funcionalidade nas áreas física, cognitiva e afetiva.

Constata-se através das respostas, que saber envelhecer é um aprendizado contínuo, é aceitar as novas limitações que o tempo traz, é não encarar a aposentadoria como um vazio, mas aprender a usar e desfrutar desse momento livre para buscar momentos de prazer. É renunciar uma antiga posição de autoridade e aceitar que um estilo de vida produtivo se fecha para que outro tipo de vida apareça: "\{...\} a saúde e a disposição 
que tenho, tanto para o trabalho, como para as atividades físicas e lazer". (Aluna C). “\{...\}estar aproveitando mais minha vida”. (Aluna B). “\{...\} liberdade”. (Aluna C). "\{...\} fazer só o que quero, quando quero, do jeito que quero." (Aluna F).

Para as mulheres do grupo, envelhecer significa ter saúde, manter uma boa qualidade de vida, que a velhice não é sinônimo de doença. Ao pensar na saúde, como um estado de razoável harmonia entre o sujeito e sua própria realidade, esta passa a ser definida pela Organização Mundial da Saúde² como um bem-estar biopsicossocial. Vê-se, então, que a saúde é um campo que abrange muito mais do que apenas a ausência de doença.

A partir de então, a saúde é vista como um "indicador de qualidade de vida, e é determinada, por sua vez, pelas condições gerais da existência". Isto envolve um processo educacional, pois a educação procura, sempre, desencadear mudanças de comportamento e exige o conhecimento da viabilidade das áreas de intervenção e a compreensão das funções e dos papéis de cada indivíduo dentro de um contexto.

A saúde sendo definida como um estado de completo bem-estar físico, mental e social, e não meramente a ausência de doença ou enfermidades, é bem lembrada pelas mulheres que responderam à pesquisa: "\{...\} envelhecer com saúde é aquela pessoa que se mantém ativa todos os dias, pratica exercícios, faz uma boa alimentação, mantém amigos e cuida da mente. "(Aluna Q).

A qualidade de vida na terceira idade pode ser influenciada por alguns aspectos, tais como: o aspecto físico, que é caracterizado pelo crescente declínio das funções dos sistemas fisiológicos comprometendo a saúde; o aspecto psicológico, caracterizado por perdas na autoimagem e autoestima: "\{...\} envelhecer com saúde para mim é manter uma boa qualidade de vida". (Aluna A).

Observa-se, inicialmente, que o envelhecer com saúde na concepção dessa aluna, é ter uma boa qualidade de vida, que depende dos novos tempos, aplicando-se ao indivíduo aparentemente saudável e diz respeito ao seu grau de satisfação com a vida nos múltiplos aspectos que interagem. Para as demais, o envelhecer com saúde significa mais que ter boa saúde, é ter a cabeça positiva, sem deixar que problemas perturbem que com boa alimentação, atividades físicas diárias, participação de atividade em grupo, ter uma vida social com bastantes amigos, fazer as coisas que gosta, são componentes importantes no envelhecer com saúde. 
Ser uma pessoa saudável não é fruto apenas do histórico familiar, de exercícios físicos regulares ou de uma boa alimentação. Na verdade, o fator determinante da saúde é a forma como se conduz a vida. É surpreendente, mas é o modo de viver o comportamento que mais influencia a saúde das pessoas. Conhecer-se melhor, lidar de uma forma saudável com sentimentos e emoções são fundamentais para uma vida equilibrada e feliz.

Em relação ao significado do grupo Maturidade Ativa para as pesquisadas, pode-se observar que as mulheres que frequentaram o grupo tinham-no como uma oportunidade de se afastarem do sedentarismo, fazer exercícios, conviver com outras pessoas, fazer novas amizades, preservar a saúde e sair da rotina.

Nesta categoria percebemos que para $44 \%$ mulheres o significado do grupo maturidade ativa foi ter um grupo, um convívio com outras mulheres, $20 \%$ das mulheres relataram que o significado esteve em ter uma ocupação e $56 \%$ responderam que foi a pratica de atividades físicas.

O idoso, no decorrer de sua vida, já transitou por diversos grupos como família, amigos, escola e trabalho, devendo ter todas as condições internas e a necessidade de se filiar a um grupo de pessoas iguais a ela.

Acredita-se, ser uma realidade o trabalho de grupo com a terceira idade, com esse ser humano, com suas potencialidades e limitações, sendo de grande importância à construção de grupos.

\footnotetext{
"Grupo é um conjunto de indivíduos ligados por constantes de espaço e tempo, articulados por mútuas representações que se propõem de forma implícita e explícita a uma tarefa que constitui sua finalidade, interatuando através de complexos mecanismos de assunção e adjudicação de papéis" ${ }^{10}$.
}

Quando o idoso, deixa ou tende a romper com grupos sociais dos quais participava, seja, por perda do trabalho ou de entes queridos, ele se isola. Portanto, o que pode ser observado é que o grupo, e não o tipo de atividade exercida passa a ter papel importante nessa fase do desenvolvimento, o que permite ao idoso reconstruir relações através do "vínculo" com outros indivíduos da mesma idade e que apresentem uma história de vida no mesmo contexto político e histórico de uma época, o que passa a ser um facilitador da interação: "\{...\} o grupo é um belo início de uma caminhada e de convívio saudável, amistoso e crescente". (Aluna R).

O significado do grupo é de grande valia, inclui o equilíbrio emocional, a autoestima e a integração social. Dentre os inúmeros fatores que podem contribuir para a obtenção 
destes resultados, a prática de atividades físicas vem assumindo um papel fundamental, tornando-se importante discutir os aspectos envolvidos no processo de envelhecimento.

Diante do aumento da longevidade e do contingente populacional, a atividade em grupo pode apresentar uma contribuição relevante para um envelhecimento saudável.

A "sociabilidade" é mais um fator encontrado, sendo identificado em vários estudos realizados com o tema motivação. Esse assunto é de muito valor, pois além da saúde física, o idoso também valoriza a parte social. A convivência com pessoas diferentes, novas amizades, combinar passeios, fazer parte de algum grupo são fatores presentes nos discursos dos idosos, fazendo-os sentirem-se mais respeitáveis, retomando um papel na sociedade: "\{...\} pela convivência com pessoas, a busca pelos mesmos objetivos". (Aluna A). "\{...\} para aumentar meu grupo de amigos e participar das atividades." (Aluna B).

No aspecto social, destacaram-se as perdas de papéis ocupacionais significativos, muitas vezes com restrição à participação no contexto, o que justifica a investigação do grupo de atividade como contribuição para um envelhecimento saudável e com qualidade.

Quando se fala em ocupação, o desligamento da rotina de anos de trabalho significa uma mudança drástica e às vezes, esta mudança é dramática pelas consequências psicológicas e morais. O sujeito deve repensar e redefinir sua vida e identidade, ao mesmo tempo em que deve assumir sua velhice e o estigma de ser inativo, da fragilidade física e a competência para produção. "...o que me levou foi essa vontade que tenho de participar de grupos, fazer exercícios, manter-me em atividades". (Aluna Y). "\{...\} com minha aposentadoria, procurei preencher o espaço, sendo suficiente e me senti melhor". (Aluna P).

A forma como os idosos vivem a aposentadoria levou-nos a ver que a "ocupação" do idoso refere-se à necessidade de "fazer uma atividade" e "ter uma ocupação", que é uma forma de reencontrar-se, tanto perante um grupo, como propriamente em seu cotidiano ${ }^{11}$.

O quadro social do idoso se caracteriza pela falta do que fazer, logo, torna-se relevante o trabalho realizado por entidade que visam o bem-estar e a ocupação de seus frequentadores.

Os programas de atividade física têm como uma das suas características o trabalho em grupo, o que propicia aos participantes a possibilidade de interação social. Este aspecto mostra-se como fonte determinante da manutenção das pessoas nos programas, evidenciando a importância do grupo social: "\{...\} a buscar uma vida mais saudável, o convívio com pessoas diferentes, a prática de exercícios". (Aluna S). 
$\mathrm{Na}$ sociedade atual o sedentarismo é um fator predominante que atinge todas as camadas sociais e faixas etárias. As atividades da vida diária na sociedade tecnicamente desenvolvida não fornecem trabalho físico suficiente para estimular o sistema cardiorrespiratório e muscular, havendo a necessidade de uma prática regular de atividade física para manter a capacidade funcional.

O sedentarismo ocorre em todas as faixas etárias, mas na velhice ele pode ser mais acentuado, devido à crença popular de que com o processo de envelhecimento deve-se diminuir a intensidade e quantidade de atividades físicas. O ser humano requer movimento, onde os resultados obtidos com um mínimo de exercícios são grandes e os benefícios incalculáveis, principalmente em se tratando do idoso ${ }^{12}$.

Os benefícios das atividades físicas estão presentes nos aspectos biológicos, psicológicos e sociais, pois ao envelhecer os idosos enfrentam problemas como: solidão, ausência de objetivos de vida e de atividades ocupacionais, sociais, de lazer e físicas. A atividade física auxilia na reintegração destes na sociedade e melhora o seu bem-estar geral.

Para conseguir os efeitos benéficos da atividade física é de grande importância a participação regular e continua. A prática de atividade física também promove a melhoria da composição corporal, a diminuição de dores articulares, o aumento da densidade mineral óssea, a melhora da utilização de glicose, o aumento da capacidade aeróbia, a melhora de força e de flexibilidade, a diminuição da resistência vascular. E, como benefícios psicossociais encontram-se o alívio da depressão, o aumento da autoconfiança e a melhora da autoestima.

As atividades realizadas no grupo do SESC são voltadas para o bem-estar físico e mental. O desenvolvimento do programa de atividades físicas é voltado para as idosas de forma que possam pratica-lo com prazer. As mulheres responderam que o grupo satisfaz suas expectativas e acreditam que possam ter atividades do tipo que as leva a uma vida mais saudável e de uma maior disposição física e mental.

O programa de atividades desenvolvido no grupo tivera algumas propostas como oportunizar a prática de atividades físicas e recreativas, buscando a manutenção da saúde e favorecendo a mudança do estilo de vida. As atividades compreendem atividades sensório-motoras envolvendo trabalhos aeróbios de baixo impacto, dança, alongamento, flexibilidade, equilíbrio, força, resistência, relaxamento, ritmo, trabalhos resistidos como a ginástica localizada entre outros. Diferentes materiais desportivos ou reciclados eram 
utilizados na ginástica, como: bolas, halteres, pesos, step, caneleiras, jornais, elástico, entre outras; com intuito de estimular os alunos nas atividades. Enfim, as atividades priorizavam a atuação das idosas buscando uma redescoberta de seu corpo, trabalhando com as possibilidades corporais, atingindo também as relações sociais.

Evidenciando esses dados, conforme se identificou na análise do assunto afirmações do tipo: "\{...\}vem de encontro as minhas necessidades". (Aluna A). "\{...\} sintome mais leve e animada." (Aluna D). "\{...\} porque desenvolvemos atividades completas, alongamentos e exercícios localizados que são muito interessantes e necessários." (Aluna F). "\{...\} estão de acordo, com atividades adequadas à nossa idade, muito entusiasmo, paciência, alegria e aptidão demonstrada pela professora." (Aluna $\mathrm{G}$ ).

A partir dos relatos analisados, as atividades desenvolvidas estavam satisfazendo as expectativas das mulheres que frequentavam o grupo e essas atividades demonstraram estarem sendo válidas para o processo de envelhecimento das mulheres que frequentavam o grupo, pois mostram-se animadas em relação as atividades propostas e frequentadoras assíduas.

Para idosas, realizar alguma prática ativa, além de contribuir na manutenção da vida ativa, também auxilia na parte social dos indivíduos ${ }^{12}$. Ainda com esse grupo de pessoas idosas os fatores externos exercem grande influência na motivação, pois as mudanças físicas e psicológicas, características do envelhecimento como a suscetibilidade à doenças, sensações de desânimo e a crença da incapacidade interferem na disposição do indivíduo para a adesão a um programa de atividade física ${ }^{9}$, podemos observar na afirmação: “ $\{\ldots\}$ sim e muito, além do trabalho corporal é também oferecido momentos de alegria, de carinho e amizade entre a professora e as colegas." (Aluna $\mathrm{H}$ ).

Assim, se a vida sedentária produz aspectos negativos ligados à saúde da mulher idosa, a pratica regular de atividade física, por outro lado, propicia uma série de benefícios que vão além do simples fortalecimento do organismo.

Em relação ao estilo de vida ativo, convém realçar que as evidências mostraram o efeito benéfico de um estilo de vida ativo, na manutenção da capacidade funcional e da autonomia física durante o processo de envelhecimento, minimizando a degeneração provocada pelo envelhecimento e, assim, propiciam uma melhoria geral na saúde e qualidade de vida. 
Os efeitos do trabalho foram evidenciados através dos próprios idosos. A integração do grupo é visível, uma vez que a procura pelo programa de atividade física é constante havendo-se a necessidade de sempre continuar.

Em se tratando da promoção da saúde, as mulheres colocaram que a pratica não se dá somente pela prática de atividade física, mas também de uma alimentação saudável, dormir bem, lazer. Esses aspectos fazem parte do envelhecer com saúde. Podemos constar nas afirmações: "\{...\} não somente, é um conjunto de atividades que nos promovem saúde, atividade física, mais atividade cultural, mais voluntariado, muitas mais. Amizades e participar de atividades sociais." (Aluna A).

"\{...\} a saúde de uma pessoa deve ser física e também mental, pois uma complementa a outra e para vivermos bem precisamos estar em paz conosco, só assim podemos transmitir aos outros nossas experiências e conhecimentos e também o amor que sentimos, dando graças pela vida que temos. " (Aluna B).

"\{...\} não todos os fatores devem ser considerados: emocional, físico, social..." (aluna C). "\{...\} não. Porque, saúde envolve muito mais. Envolve prática de atividade física, o viver bem no dia-a-dia, o cuidado com a saúde, através de exames médicos, etc." (aluna D). "\{...\} não, a promoção da saúde é a harmonia que atende ao preceito: mente sana in corporesano". (Aluna E).

O projeto realizado pelo SESC Maturidade Ativa tem como missão: Construir um novo significado social para o envelhecimento e tem como princípios básicos: Valorização dos sócios, sua vida, seu espaço e seus interesses; Promoção da saúde física e mental; Promoção do intercâmbio cultural, da convivência e da amizade; Estímulo ao envolvimento social; Desenvolvimento do trabalho comunitário e solidário; "Um novo jeito de envelhecer"; Construir um novo significado social, com uma nova abordagem para o envelhecimento bem-sucedido, através de ações que estimulem o convívio e a valorização de pessoas com idade.

O projeto concede o direito de participar e de interagir em conjunto, vincular-se a um grupo traz à pessoa uma nova vivência em que se torna sujeito do seu próprio papel e desenvolve sua autonomia pessoal, ajuda a mudar valores, muitas vezes superados, e os torna mais receptivos as novas mudanças e a modernidade.

O projeto proporciona ao SESC uma maior visibilidade da instituição e de seus projetos. Podemos observar que o grupo Maturidade Ativa atinge seus objetivos e fortalece a imagem do SESC através dos relatos das mulheres: 
"\{...\} foi sem dúvida algo marcante que aconteceu no SESC, pois os grupos que atualmente existem, trabalham em prol do bem-estar do idoso. O SESC disponibilizou princípios sérios para a qualidade de vida do idoso, buscando sempre a sua valorização. Acho que foi uma brilhante ideia do SESC, pois está dando oportunidade as pessoas de fazer algo por si próprias, conhecer novos amigos, fazendo a sua vida ser mais alegre e descontraída" (Aluna B).

“\{...\} o grupo é um belo início de uma caminhada e de convívio saudável, amistoso e crescente, é uma iniciativa que só poderia ser do SESC" (aluna A).

“....\} por estar ligado a uma entidade como o SESC, a sua maneira o grupo promove uma maior convivência entre seus colegas e possui um grande diferencial que é a sua função social de auxiliar a outras pessoas que realmente necessitam de auxílio formando assim um grupo mais unido, alegre e feliz". (Aluna C).

Esta proposta de trabalho veio a suprir as necessidades encontradas nestes grupos de convivência. Atualmente trabalha-se de uma forma vertical entre coordenadores e alunos, atuando de forma que as pessoas maiores de 50 anos se auto gerenciem através de atividades biopsicossociais. Com os depoimentos, constatamos a importância deste trabalho, na medida em que todas citam o projeto de forma positiva e otimista, pois as mudanças que aconteceram em suas vidas foram muito significativas.

\section{CONCLUSAO}

A partir da análise dos resultados observou-se que, para as mulheres que frequentaram o Grupo Maturidade Ativa, este possui uma contribuição significativa no equilíbrio emocional, na autoestima, na integração social, na ocupação, na prática de atividade física, promoção e prevenção da saúde e um estilo de vida ativo.

Para as participantes do Grupo Maturidade Ativa o envelhecimento representa amadurecer com saúde, a busca por uma vida mais saudável, ativa, através de atividades físicas, convívio social e estabelecimento de novas amizades e ocupação a mais no seu dia-a-dia.

A participação no Grupo representa a importância de se ter e manter um grupo de terceira idade. Desta forma o grupo aparece como um meio favorecedor da socialização com consequentes trocas afetivas e motivações para a busca de novas atividades e realização de antigos projetos. As mulheres buscam mais uma acolhida afetiva com 0 encontro de pessoas e construção de novas amizades. 
As atividades realizadas no grupo satisfazem as expectativas, vindo ao encontro com o que buscam e acreditam que as atividades as levam a uma vida mais saudável, com maior disposição física e mental.

Partindo das análises realizadas pode-se constatar que as mulheres que frequentaram o grupo Maturidade Ativa do SESC Santo Ângelo RS estavam satisfeitas com o propósito do grupo. Entende-se que projetos direcionados ao idoso, ou seja, projetos que buscam uma maior e melhor expectativa de vida implicam numa construção que contemple vários fatores relacionados a saúde e qualidade de vida, principalmente pelo fato de poderem participar de um grupo, trazem melhorias no bem-estar e satisfação a estas pessoas. Portanto, para essas mulheres, participar de um grupo é mais importante do que a própria atividade física.

Os dados encontrados neste estudo suportam a tese da necessidade do estímulo de atividades físicas grupais para que as mulheres se sintam mais motivadas, felizes e capazes de realizar suas atividades, contribuindo para um envelhecer com saúde, disposição e integração.

O grupo e as atividades realizadas foram ao encontro aos objetivos propostos pelo Projeto do SESC de Santo Ângelo, atendendo os aspectos sociais, biológicos e psicológicos, sendo esses fatores preponderantes no processo de envelhecimento.

\section{REFERENCIAS}

1. AMARAL, J.R.G., FILHO, W.J., Avaliação Geral do Idoso: Manual da Liga do GAMIA- São Paulo: Editora Atheneu, 2005.

2. OMS - World Health Organization, Relatório Mundial sobre Envelhecimento e Saúde. Disponível em: http://apps.who.int/iris/bitstream/handle/10665/186468/WHO_FWC_ALC_15.01_por.pdf;jsessionid=0E46 7B55F34BF587A2A19B695C83E0F1? sequence=6. Acesso em: 15 dez. 2018.

3. MOREIRA, C.A., Atividade física na maturidade: avaliação e prescrição de exercícios - Rio de Janeiro: Shape, 2001.

4. NAHAS, Markus V. Atividade Física, Saúde e Qualidade deVida. 3o.edição. Londrina: Midiograf, 2003.

5. VICTOR, J. F. et al. Grupo feliz idade: cuidado de enfermagem para a promoção da saúde na terceira idade. RevEscEnferm USP 2007; 41(4):724-30. Disponível em: http://www.scielo.br/pdf/reeusp/v41n4/25.pdf . Acesso em: 15 dez. 2018.

6. MAZO, G. Z., LOPES, M. A., BENEDETI, T.B., Atividade Física e o idoso - Concepção Gerontológica. Porto Alegre: Sulina, 2001.

7. THOMAS, J. R., NELSON, J. K., Métodos de Pesquisa em Atividades Física. 3ํe edição. Porto Alegre: Artmed, 2002. 
DOI: 10.18606/2318-1419/amazonia.sci.health.v7n3p22-36 Revista Amazônia: Science \& Health

2019, Vol. 7, № 3

ISSN: $2318-1419$
Ferraz LCP. Rodrigues C. Farencena EZP. Deon VR.

Grupo maturidade ativa e o seu significado para as alunas do grupo do Sesc de Santo Ângelo RS

8. STUART-HAMILTON, Ian. A psicologia do envelhecimento: uma introdução. 3. ed. Porto Alegre: Artmed, 2002.

9. NERI, A.L., Qualidade de Vida e Idade Madura - Campinas, SP: Papirus, 1993. Revista AMRIGS, Porto Alegre, 48 (4): 276-277, out.-dez. 2004

10.MAXIMINO, Viviane Santalúcia. Grupos de atividades com pacientes psicóticos. São José dos Campos, SP: Univap, 2001.

11.CASTRO, O. P., Velhice que idade é essa?: Uma construção psicossocial do envelhecimento - Porto Alegre: Síntese, 1998

12.MIRANDA, Francislaine Domingues. Adesão e Permanência de Idosos em um Projeto de Atividade Física no Centro de Desportos da UFSC. 2016. 39f. Curso de Bacharelado em Educação Física, Centro de Desportos, Universidade Federal de Santa Catarina, Florianópolis. 